\title{
Commentary: Current Status and Future of Corneal Xenotransplantation
}

Mee Kum Kim ${ }^{1,2,3}$

${ }^{1}$ Department of Ophthalmology, Seoul National University College of Medicine, Seoul, Korea

${ }^{2}$ Laboratory of Ocular Regenerative Medicine and Immunology, Seoul Artificial Eye Center, Seoul National University Hospital Biomedical Research Institute, Seoul, Korea

${ }^{3}$ Xenotransplantation Research Center, Seoul National University College Of Medicine and Clinical Research Institute, Seoul National University Hospital, Seoul, Korea "Corresponding author: Mee Kum Kim, Department of Ophthalmology, Seoul National University College of Medicine, 103 Daehak-ro Jongno-gu, 110-799 Seoul, Korea, Tel: 82-2-2072-2665; Fax: 82-2-741-3187; E-mail: kmk9@snu.ac.kr

Received date: May 17, 2016; Accepted date: June 13, 2016; Published date: June 20, 2016

Copyright: (C) 2016 Kim MK. This is an open-access article distributed under the terms of the Creative Commons Attribution License, which permits unrestricted use, distribution and reproduction in any medium, provided the original author and source are credited.

\section{Commentary}

Corneal transplantation is the treatment of choice for late stage of corneal decompensation [1]. According to "Cost-benefit analysis of corneal transplant", which has been prepared by Eye Bank Association of America (EBAA) and reported by the Lewin group in 2013, net lifetime benefit from the transplantation is $\$ 118,000$, while, the medical cost of the transplant is $\$ 16,500$. However, corneal donation does not meet the demand for corneal transplantation in developing countries and the number of the eligible cornea will be reduced in the future aged societies of the developed countries $[2,3]$. Another reason to seek a substitute for allograft is that ethical concerns have been raised about organ trafficking and violation of human rights [4-7]. There is wide range of suspicion of alleged trafficking in organs harvested from prisoners or Falun Gong practitioners [4,8]. In fact, in a symposium of the International Xenotransplantation Association (IXA) at Melbourne in 2015, we happened to meet the protesters against allotransplantation and organ trafficking in front of the convention center because of the sudden disappearances of Falun Gong practitioners (Figure 1). Therefore, a pursuit for alternatives seems to be the right approach with respect to the unmet need and recovery of humanism.

The latest technical development has allowed multiple competing approaches including the potential for xenotransplantation to get one step closer to a clinical trial [9-14]. The current stem cell technology is able to develop corneal epithelial expansion from human induced pluripotent stem cells (iPS) for the corneal surface reconstruction $[15,16]$. The development of bioengineered corneal implant is still in progress as a substitute for stromal defect [17-19]. For a replacement with a full thickness corneal graft, xenotransplantation seems to be a most realistic option along with the recent progress in gene editing made by CRISPR-Cas9 technology [12-20]. Given that zoonotic infection by Porcine Endogenous Retroviruses (PERVs) and consequent life-long management are major hurdles to xenotransplantation [21-23], genome-wide inactivation of PERVs offers us promise for clinical application of xenotransplantation. In addition, the first clinical trial of porcine islet cell transplantation has shown no transmission of the PERV or other porcine microorganisms, suggesting the safety of the xenotransplantation [24]. Recent reports analyzed the results of pig-to-non human primate xenotransplantation, which included encouraging outcomes of both partial- and fullthickness corneal xenotransplantation [12,25-26]. Until now, corneal xenotransplantation requires stronger immunosuppression than steroids, regardless of the type of pigs (wild-type or geneticallyengineered) in these reports.

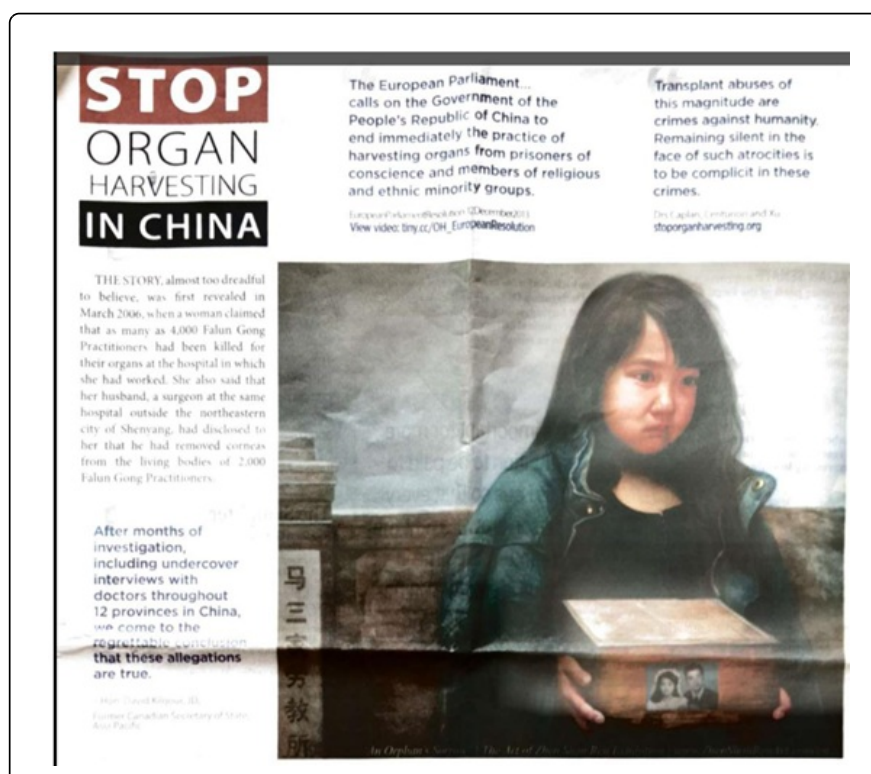

Figure 1: A flyer which was given by the protesters describes alleged corneal harvesting from 2,000 of Falun Gong Practinioners and shows a picture of an orphan who lost her parents from the organ trafficking.

Nevertheless, in our current study, a clinically applicable immune suppressive protocol (basiliximab +tacrolimus +rituximab) has achieved mid-term survival of corneal xenotransplantation using SNU miniature wild-type pigs so far, thus, opening a door to a clinical trial (unpublished data). To achieve a success of corneal xenotransplantation, the anatomical barrier as well as immunological challenges should be overcome. Grafts from Seoul National University (SNU) miniature pigs, which have a mean thickness of $853 \mu \mathrm{m}$, have been shown to survive after transplantation into non-human primates, in whom the cornea has a mean thickness of $490 \mu \mathrm{m}$ [27]. None of the papers have documented successful transplantation of a corneal graft with a thickness of more than $1000 \mu \mathrm{m}$. Both tensile property and refractive power of the pig cornea are not the limiting factors in pig-tonon human primate xenotransplantation. From an immunological aspect, the distribution of galactose- $\alpha 1,3$-galactose [Gal] or non-Gal (e.g., N-glycolylneuraminic acid [NeuGc]) in the cornea may be involved in the humoral and cellular immune responses [12]. Given that the in vitro immune responses to corneal endothelial cells (CECs) obtained from a1,3-galactosyltransferase gene-knockout (GTKO) pigs, 
Page 2 of 3

GTKO/ hCD46 knock-in pigs, or human dominant-negative class II transactivator (CIITA-DN) transgenic pigs are attenuated compared to the in vitro immune responses to CECs obtained from wild-type pigs, genetically-engineered pigs may be a potential donor in clinical corneal xenotransplantation. Finally, functionally enough endothelial cell density is required to maintain corneal transparency.

To conduct a clinical trial of corneal xenotransplantation, ethical and regulatory guidelines are mandatory. The first guidelines which had been established by a Korean group formed an initiative to develop the IXA consensus statements on conditions for undertaking clinical trials of corneal xenotransplantation which include (1) ethical requirement, (2) quality control of source pigs, (3) quality control of porcine corneal products, (4) preclinical efficacy and safety data that are required to justify a clinical trial, (5) strategies to prevent PERV transmission and (6) patient selection and informed consent [28, 29]. Guidelines for clinical trials of corneal xenotransplantation follow the basic principles of the consensus statement on conditions for undertaking clinical trials of porcine islet cell products in type 1 diabetes published by the IXA in 2009[30]. Thereafter, the IXA consensus statement on conditions for undertaking clinical trials of porcine islet products has been firstly revised this year [22,23,31-36]. New or under-appreciated topics have been addressed, and previous topics, regarding regulatory framework, genetic modification of the source pig, recipient monitoring for preventing disease transmission, patient selection, porcine islet product manufacturing, and quality control of source pigs, have been updated, based on the current scientific advances. Some of the topics should be discussed for undertaking clinical trials of corneal xenotransplantation. For example, (1) in source pigs, PERV-C negative donor animals could be considered preferable, and animal selection criteria should be primarily based on low PERV expression levels and lack of infectivity. (2) The assessment of clinical trial protocols using genetically modified pig products needs to be done on a case-by-case basis. (3) Preclinical efficacy is revised by the finding that survival in 4 of 6 (or 5 of 8 ) consecutive experiments would be sufficient to indicate potential success of a clinical trial. (4) Clinically relevant microorganisms should be included in pig screening programs. (5) Microorganisms absent in the donor animals by sensitive microbiological examination do not need to be monitored in the transplant recipient. Given that substantial scientific progress has been made, the international consensus statement on corneal xenotransplantation is expected to be updated with respect to these under-appreciated issues or previous topics.

In summary, the current development of technologies suggests that the coming years promise much for the field of xenotransplantation. In fact, clinical trials of xenotransplantation using acellular porcine corneal stroma or encapsulated neonatal porcine islets have already been conducted and safety concerns have not been reported so far $[37,38]$. With regard to the regulatory aspects and preclinical efficacies, both islet and corneal xenotransplantation have become clinically realistic options as human substitutes and progress in recent research is promising to advance this xenotransplantation field $[11,12,39]$.

\section{References}

1. Tan DT, Dart JK, Holland EJ, Kinoshita S (2012) Corneal transplantation. Lancet 379: 1749-1761.

2. Hara H, Cooper DK (2011) Xenotransplantation-the future of corneal transplantation? Cornea 30: 371-378.
3. Lamm V, Hara H, Mammen A, Dhaliwal D, Cooper DK, et al. (2014) Corneal blindness and xenotransplantation. Xenotransplantation 21: 99-114.

4. Treasure T (2007) The Falun Gong, organ transplantation, the holocaust and ourselves. Journal of the Royal Society of Medicine 100: 119-121.

5. Beck DC, Choi KR, Munro-Kramer ML, Lori JR (2016) Human Trafficking in Ethiopia: A Scoping Review to Identify Gaps in Service Delivery, Research, and Policy. Trauma, violence \& abuse.

6. Cousins S (2016) Nepal: organ trafficking after the earthquake. Lancet 387: 833.

7. Yousaf FN, Purkayastha B (2016) Social world of organ transplantation, trafficking and policies J public health policy 37: 190-199.

8. Northam HL (2016) Hard to Believe : Produced by Ken Stone and Irene Silber 2015 Swoop Films and Stone Soup Productions (New York, 56 minutes, unrated) J Bioeth Inq.

9. Mou L, Chen F, Dai Y, Cai Z, Cooper DK, et al. (2015) Potential alternative approaches to xenotransplantation. Int J Surg 23: 322-326.

10. Reardon S (2015) New life for pig-to-human transplants. Nature 527: 152-154.

11. Michel SG, Madariaga ML, Villani V, Shanmugarajah K (2015) Current progress in xenotransplantation and organ bioengineering. Int J Surg 13: 239-244.

12. Kim MK, Hara H (2015) Current status of corneal xenotransplantation. Int J Surg 23: 255-260.

13. Reichart B, Guethoff S, Brenner P, Poettinger T, Wolf E, et al. (2015) Xenotransplantation of Cells, Tissues, Organs and the German Research Foundation Transregio Collaborative Research Centre 127. Adv Exp Med Biol 865: 143-155.

14. Perkel JM (2016) Xenotransplantation makes a comeback. Nature biotechnology 34: 3-4.

15. Hayashi R, Ishikawa Y, Ito M, Kageyama T, Takashiba K, et al. (2012) Generation of corneal epithelial cells from induced pluripotent stem cells derived from human dermal fibroblast and corneal limbal epithelium. PloS one 7: e45435.

16. Hayashi R, Ishikawa Y, Sasamoto Y, Katori R, Nomura N, et al. (2016) Coordinated ocular development from human iPS cells and recovery of corneal function. Nature 531: 376-380.

17. Mirazul Islam M, Cepla V, He C, Edin J, Rakickas T, et al. (2015) Functional fabrication of recombinant human collagenphosphorylcholine hydrogels for regenerative medicine applications. Acta biomaterialia 12: 70-80.

18. Hayes S, Lewis P, Islam MM, Doutch J, Sorensen T, et al. (2015) The structural and optical properties of type III human collagen biosynthetic corneal substitutes. Acta biomater 25: 121-130.

19. Buznyk O, Pasyechnikova N, Islam MM, Iakymenko S, Fagerholm P, et al. (2015) Bioengineered Corneas Grafted as Alternatives to Human Donor Corneas in Three High-Risk Patients. Clin Transl Sci 8: 558-562.

20. Yang L, Guell M, Niu D, George H, Lesha E, et al. (2015) Genome-wide inactivation of porcine endogenous retroviruses (PERVs). Science 350: 1101-1104.

21. Denner J, Schuurman HJ, Patience C (2009) The International Xenotransplantation Association consensus statement on conditions for undertaking clinical trials of porcine islet products in type 1 diabetes-chapter 5: Strategies to prevent transmission of porcine endogenous retroviruses. Xenotransplantation 16: 239-248.

22. Denner J, Tonjes RR, Takeuchi Y, Fishman J, Scobie L, et al. (2016) First update of the International Xenotransplantation Association consensus statement on conditions for undertaking clinical trials of porcine islet products in type 1 diabetes-Chapter 5: recipient monitoring and response plan for preventing disease transmission. Xenotransplantation 23: 53-59.

23. Spizzo T, Denner J, Gazda L, Martin M, Nathu D, et al. (2016) First update of the International Xenotransplantation Association consensus statement on conditions for undertaking clinical trials of porcine islet products in type 1 diabetes-Chapter 2a: source pigs-preventing xenozoonoses. Xenotransplantation 23: 25-31. 
Citation: Kim MK (2016) Commentary: Current Status and Future of Corneal Xenotransplantation. J Transplant Technol Res 6: 163. doi: 10.4172/2161-0991.1000163

Page 3 of 3

24. Wynyard S, Nathu D, Garkavenko O, Denner J, Elliott R, et al. (2014) Microbiological safety of the first clinical pig islet xenotransplantation trial in New Zealand. Xenotransplantation 21: 309-323.

25. Cooper DK, Satyananda V, Ekser B, van der Windt DJ, Hara H, et al. (2014) Progress in pig-to-non-human primate transplantation models (1998-2013): a comprehensive review of the literature. Xenotransplantation 21: 397-419.

26. Cooper DK, Ezzelarab MB, Hara H, Iwase H, Lee W, et al. (2016) The pathobiology of pig-to-primate xenotransplantation: a historical review. Xenotransplantation 23: 83-105.

27. Choi HJ, Lee JJ, Kim DH, Kim MK, Lee HJ, et al. (2015) Blockade of CD40-CD154 costimulatory pathway promotes long-term survival of full-thickness porcine corneal grafts in nonhuman primates: clinically applicable xenocorneal transplantation. Am J Transplant 15: 628-641.

28. Kim MK, Lee JJ, Choi HJ, Kwon I, Lee H, et al. (2013) Ethical and regulatory guidelines in clinical trials of xenocorneal transplantation in Korea; the Korean xenocorneal transplantation consensus statement. Xenotransplantation 20: 209-218.

29. Kim MK, Choi HJ, Kwon I, Pierson RN, 3rd, Cooper DK, et al. (2014) The International Xenotransplantation Association consensus statement on conditions for undertaking clinical trials of xenocorneal transplantation. Xenotransplantation 21: 420-430.

30. Hering BJ, Cooper DK, Cozzi E, Schuurman HJ, Korbutt GS, et al. (2009) The International Xenotransplantation Association consensus statement on conditions for undertaking clinical trials of porcine islet products in type 1 diabetes-- executive summary. Xenotransplantation 16: 196-202.

31. Cooper DK, Bottino R, Gianello P, Graham M, Hawthorne WJ, et al. (2016) First update of the International Xenotransplantation Association consensus statement on conditions for undertaking clinical trials of porcine islet products in type 1 diabetes-Chapter 4: pre-clinical efficacy and complication data required to justify a clinical trial. Xenotransplantation 23: 46-52.

32. Cowan PJ, Ayares D, Wolf E, Cooper DK (2016) First update of the International Xenotransplantation Association consensus statement on conditions for undertaking clinical trials of porcine islet products in type 1 diabetes-Chapter 2b: genetically modified source pigs. Xenotransplantation 23: 32-37.

33. Cozzi E, Tonjes RR, Gianello P, Buhler LH, Rayat GR, et al. (2016) First update of the International Xenotransplantation Association consensus statement on conditions for undertaking clinical trials of porcine islet products in type 1 diabetes - Chapter 1: update on national regulatory frameworks pertinent to clinical islet xenotransplantation. Xenotransplantation 23: 14-24.

34. Hering BJ, Cozzi E, Spizzo T, Cowan PJ, Rayat GR, et al. (2016) First update of the International Xenotransplantation Association consensus statement on conditions for undertaking clinical trials of porcine islet products in type 1 diabetes-Executive summary. Xenotransplantation 23: 3-13.

35. Hering BJ, O'Connell PJ (2016) First update of the International Xenotransplantation Association consensus statement on conditions for undertaking clinical trials of porcine islet products in type 1 diabetesChapter 6: patient selection for pilot clinical trials of islet xenotransplantation. Xenotransplantation 23: 60-76.

36. Rayat GR, Gazda LS, Hawthorne WJ, Hering BJ, Hosking P, et al. (2016) First update of the International Xenotransplantation Association consensus statement on conditions for undertaking clinical trials of porcine islet products in type 1 diabetes - Chapter 3: Porcine islet product manufacturing and release testing criteria. Xenotransplantation 23: 38-45.

37. Zhang MC, Liu X, Jin Y, Jiang DL, Wei XS, et al. (2015) Lamellar keratoplasty treatment of fungal corneal ulcers with acellular porcine corneal stroma. Am J Transplant 15: 1068-1075.

38. Matsumoto S, Tan P, Baker J, Durbin K, Tomiya M, et al. (2014) Clinical porcine islet xenotransplantation under comprehensive regulation. Transplant Proc 46: 1992-1995.

39. Matsumoto S, Tomiya M, Sawamoto O (2016) Current status and future of clinical islet xenotransplantation. J Diabetes 8: 483-983. 